\title{
Advances in the Lightweight Air-Liquid Composite Heat Exchanger Development for Space Exploration Applications
}

\author{
E. Eugene Shin ${ }^{1}$, J. Chris Johnston ${ }^{2}$, and Daniel Haas ${ }^{3}$ \\ NASA Glenn Research Center, 21000 Brookpark Rd., Cleveland, OH 44135
}

\begin{abstract}
An advanced, lightweight composite modular Air/Liquid (A/L) Heat Exchanger (HX) Prototype for potential space exploration thermal management applications was successfully designed, manufactured, and tested. This full-scale Prototype consisting of 19 modules, based on recommendations from its predecessor Engineering Development unit (EDU) but with improved thermal characteristics and manufacturability, was $11.2 \%$ lighter than the EDU and achieves potentially a $42.7 \%$ weight reduction from the existing state-of-the-art metallic HX demonstrator. However, its higher pressure drop (0.58 psid vs. 0.16 psid of the metal HX) has to be mitigated by foam material optimizations and design modifications including a more systematic air channel design. Scalability of the Prototype design was validated experimentally by comparing manufacturability and performance between the 2 module coupon and the 19-module Prototype. The Prototype utilized the thermally conductive open-cell carbon foam material but with lower density and adopted a novel highefficiency cooling system with significantly increased heat transfer contact surface areas, improved fabricability and manufacturability compared to the EDU. Even though the Prototype was required to meet both the thermal and the structural specifications, accomplishing the thermal requirement was a higher priority goal for this first version. Overall, the Prototype outperformed both the EDU and the corresponding metal HX, particularly in terms of specific heat transfer, but achieved $93.4 \%$ of the target. The next generation Prototype to achieve the specification target, 3,450 W would need 24 core modules based on the simple scaling factor. The scale-up Prototype will weigh about $14.7 \mathrm{Kg}$ vs. 21.6 $\mathrm{Kg}$ for the metal counterpart. The advancement of this lightweight composite HX development from the original feasibility test coupons to EDU to Prototype is discussed in this paper.
\end{abstract}

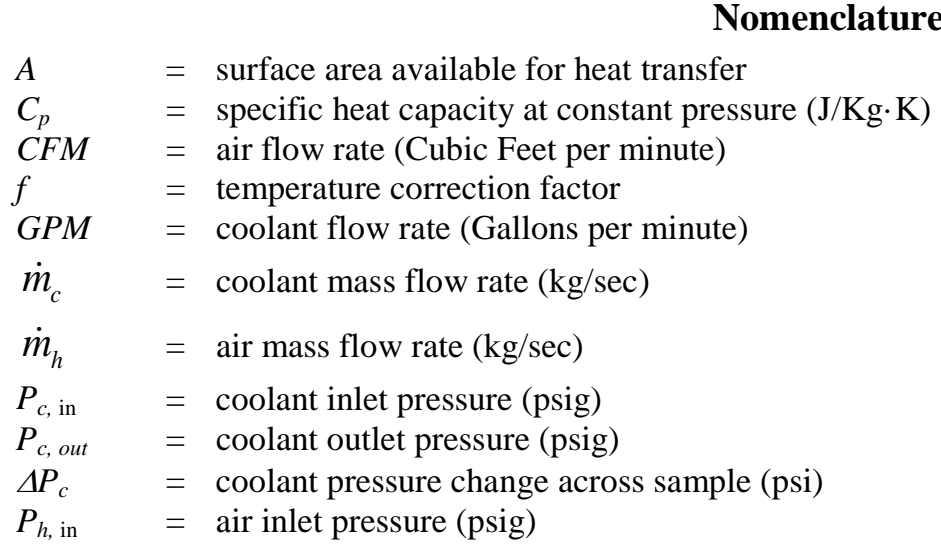

\footnotetext{
${ }^{1}$ Principal Scientist, Research Team Manager, Ohio Aerospace Institute (OAI), Materials-Polymers, NASA John H. Glenn Research Center, 21000 Brookpark Rd., MS 49-1, Cleveland, Ohio 44135.

${ }^{2}$ Chemical Engineer, Polymers Branch, Structures and Materials Division, NASA John H. Glenn Research Center, 21000 Brookpark Rd., MS 49-3, Cleveland, Ohio 44135.

${ }^{3}$ Engineering Technician, Space Combustion \& Materials Branch, NASA John H. Glenn Research Center, 21000 Brookpark Rd., Cleveland, Ohio 44135
} 


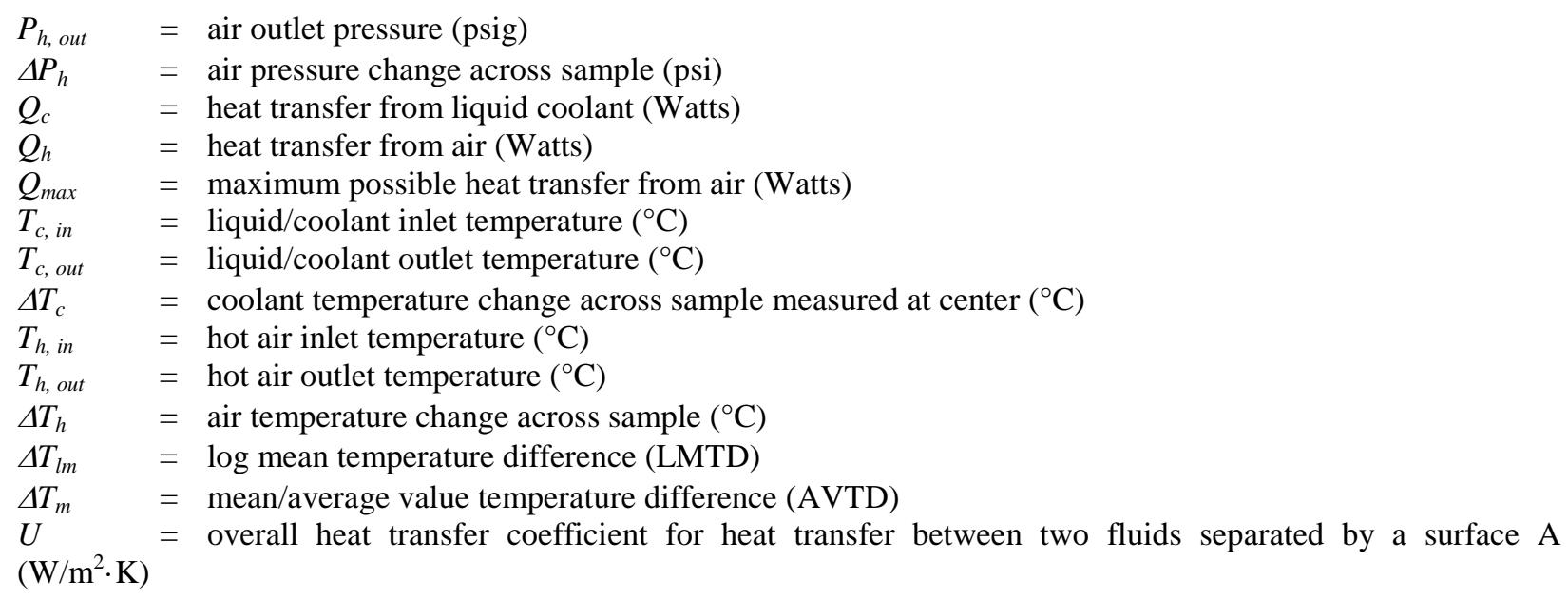

\section{Introduction}

T IGHTWEIGHT, high performance heat exchangers can certainly benefit payload design in various space Lehicles to manage excessive heat and thus cost reduction. Led by NASA-JSC, efforts to develop and demonstrate a lightweight composite heat exchanger were initiated. This paper presents our current efforts in developing the first generation prototype based on findings and recommendations from the previous engineering development unit (EDU) which was reported earlier ${ }^{1}$. However, the primary goal of the first Prototype was only to meet the thermal specifications, thus no systematic structural evaluations were performed on the design or materials used even though various concepts and approaches were developed and implemented based on the structural specifications. At the beginning of this project, feasibility was demonstrated for design concepts, materials, manufacturability, and thermal performance evaluation using a simple basic coupon ${ }^{2}$. In this study, the development of a light weight, high efficiency air-liquid (A/L) heat exchanger (HX) was attempted using polymer composites and carbon foam materials. Subscale HX panels were fabricated and tested to demonstrate the feasibility of the composite $\mathrm{HX}$ for various space exploration thermal management applications including Orion CEV and Altair. The basic design employed polymer composites for the casing and open-cell carbon foam core as the fin structure in order to develop the HX as the unit cell of a modular system. A total of seven panel designs were investigated varying the foam density/porosity, core channel configuration, composite casing material and composite processing technique. The specific objectives were to select optimum materials, designs, and to optimize fabrication procedures, as well as assess the performance and manufacturability of each of these individual design concepts for future scale-up into a full-size prototype. Since then, the EDU of the lightweight composite A/L space HX was successfully designed and manufactured. The EDU achieved $~ 37 \%$ weight reduction compared to the metal counterpart. The EDU was developed by multi-team efforts via NASA-Industry collaborations. Carbon foam development leveraged with GrafTech-OAI 3-yr program, "development of next generation 'graphitic-carbon' heat exchange materials for air- and spacecraft" funded via a federal appropriation in the FY2008 Defense Bill.

Thermally conductive open cell graphite foam materials have been extensively investigated and used as a fin structure in various air cooling systems for automotive and electronics applications because of their high thermal conductivity especially through the skeletal ligaments, large heat transfer surface, high open porosity with low pressure drop, and light weight. ${ }^{2-9}$

The metallic HX demonstrator developed by NASA-JSC was used as a baseline HX for this study. The metallic demonstrator was designed and fabricated by a private company and details of the core design were not available.

\section{Materials Used for $\mathrm{A} / \mathrm{L}$ HX Prototype}

Materials used for the Prototype were somewhat different than those used for the EDU. The carbon foam was supplied by GrafTech International. It was developmental low density foam with the following properties: $~ 0.12$ g/cc density, 95\% Total Porosity, $32 \mathrm{~W} / \mathrm{mK}$ bulk thermal conductivity (TC), and 1.82E-09 $\mathrm{m}^{2}$ Permeability. For the cooling system, all components were made of type 316 stainless steel including facesheets, welded \& drawn tubes, cold formed rectangular tubes for manifolds, and the internal fin (Lazy Ruffled Fin, Robinson Fin Machine, Inc, Kenton, Ohio). The stainless steel was selected due to its compatibility with the de-ionized cooling water. The cooling jackets were assembled via a high temperature furnace brazing processes using a 1.0 mil thick Nickel Braze foil, AMS 4777 (Bni-2). A $183{ }^{\circ} \mathrm{C}$ melting commercial electronic solder was used to seal pin holes or leaks on the 
brazed cooling jackets and to connect inlet and outlet tubes to the manifolds. The composite housing was fabricated with PATZ F1 (93C cure toughened epoxy)/T700 carbon -fiber (12K tow) fabric prepreg tape with a low-cost nanocomposite tooling via autoclave cure processes. Dylon graphite cement with phenolic binder diluted with MEK solvent was used to bond cooling jackets and carbon foam modules. The composite housing was assembled with Nylon bolts and nuts, and sealed with a silicon rubber gasket and RTV. Various thicknesses of weather-chemical resistant Santoprene rubber sheets were inserted between the HX core and composite housing as a spacer and insulator.

\section{Design and Manufacturing of Prototype}

Similar to the EDU, the Prototype was designed as a modular system. The prototype was, however, based on the plate \& frame type compact HX concept instead of the shell \& Tube type used in the EDU. It was designed to improve primarily thermal performance and manufacturability based on recommendations from the EDU. The Prototype utilized the thermally conductive open-cell carbon foam material but with lower density and adopted a novel high-efficiency cooling system with significantly increased heat transfer contact surface areas, improved fabricability and manufacturability, which maintained the overall weight reduction over the EDU. Figure 1 shows the unit module on top and front view. It consisted of cooling jacket, liquid inlet and outlet tubes and manifolds, and carbon foam layers. The dimensions of the unit were not listed due to a proprietary issue, but optimized for its overall performance, particularly thicknesses of cooling jacket and carbon foam core, thus their volumetric ratio. The carbon foam layers were surrounding the cooling jacket and intimately bonded using the thermally conductive graphite cement. This foam core was used as a passageway of air. Hot air was cooled while passing through the foam core which can be considered as a fin with three-dimensional pathways and infinite surface area. The carbon foam modules contained small diameter, semi-thru circular holes along the air flow direction from both ends as an air channel to mitigate the potentially large air pressure drop.

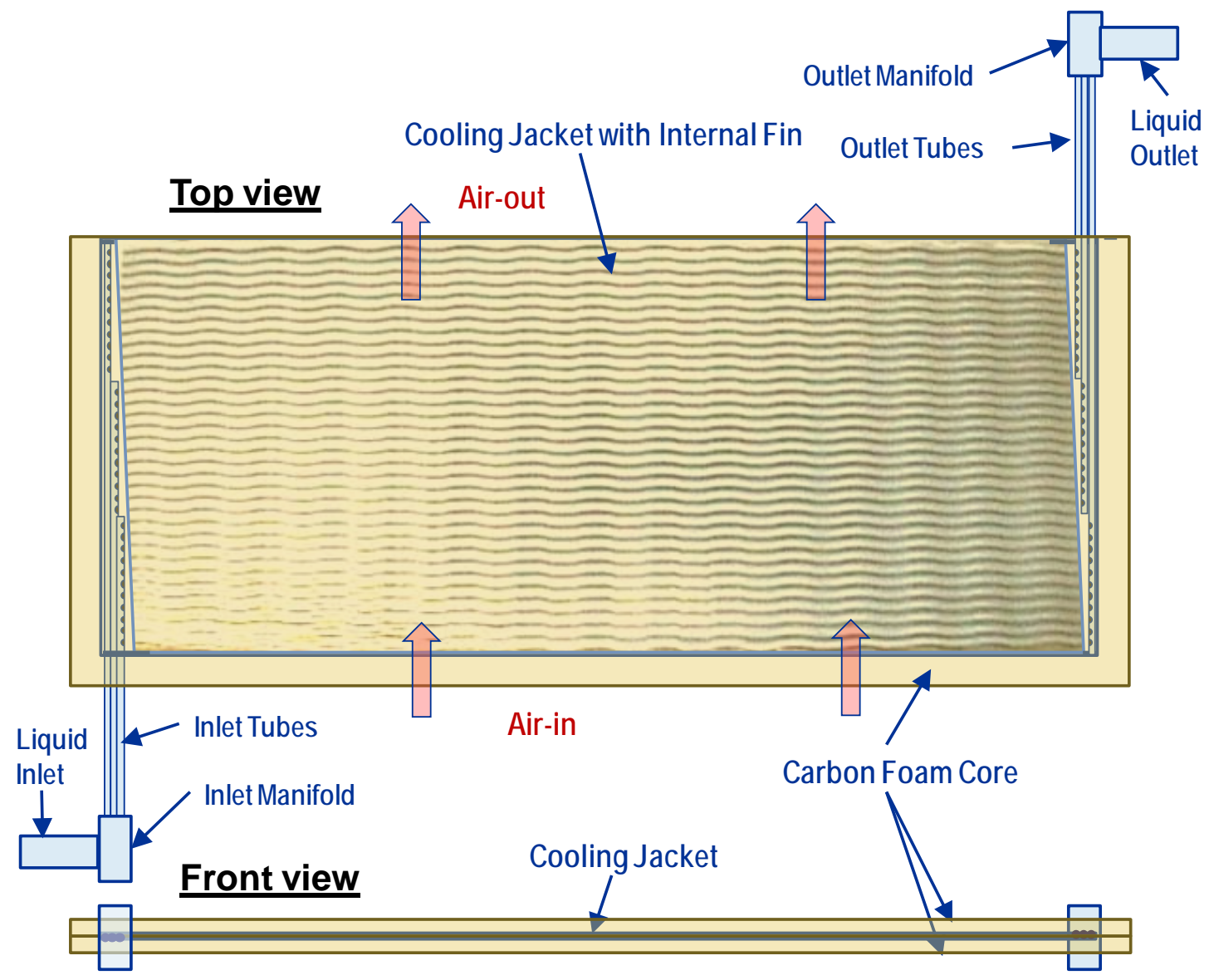

Figure 1. Schematic drawings of unit module design for the composite A/L HX Prototype. 
The cooling jacket was comprised of facesheets (top and bottom with edge lips), internal fin, and parts of the inlet and outlet tubes. The internal fin was used to reinforce the cooling jacket to sustain the required internal pressure as well as to improve heat transfer efficiency via uniform distribution across the width, with multiple wavy channels, and flow rate while maintaining a low pressure drop. The inlet and outlet tubes contained small holes on the exposed area facing the internal fin but the end was capped, controlling flow direction and distribution. The size and number of holes were optimized for flow characteristics. The uniform liquid flow distribution and rate across all channels of the internal fin were experimentally verified with direct monitoring of the liquid flow. The prototype adopted a cross-flow configuration mostly for manufacturability with minimal expense of thermal performance.

The full-scale Prototype was determined to have a total of 19 modules based on weight and thermal performance prediction analysis, specifically in terms of total heat transfer surface area between the liquid and the air side with respect to the required specifications. The overall design was thoroughly examined for fabricability and manufacturability. The resulting Prototype installed with the composite housing, Fig 2, maintained its overall volume comparable to the metal HX demonstrator. Figure 2 shows overall features of the full-scale Prototype from two views including the air-inlet plenum with an air deflector, HX core, and the air-outlet plenum. The core as viewed from the outlet plenum shows multiple laminated modules and air channels on foam layers. The liquid inlet and outlet on the external manifolds connected to the inlet or outlet tubes are also shown in the pictures. Multiple thermocouples (Type T Stick-on thermocouple from Omega), a total of 19, one per cooling jacket, were installed on the top surface of the cooling jacket, center of the width near the outlet side, to monitor liquid flow distribution among the 19 cooling jackets. Their leads were brought out through slots on the side of the air-outlet plenum and sealed with epoxy potting.

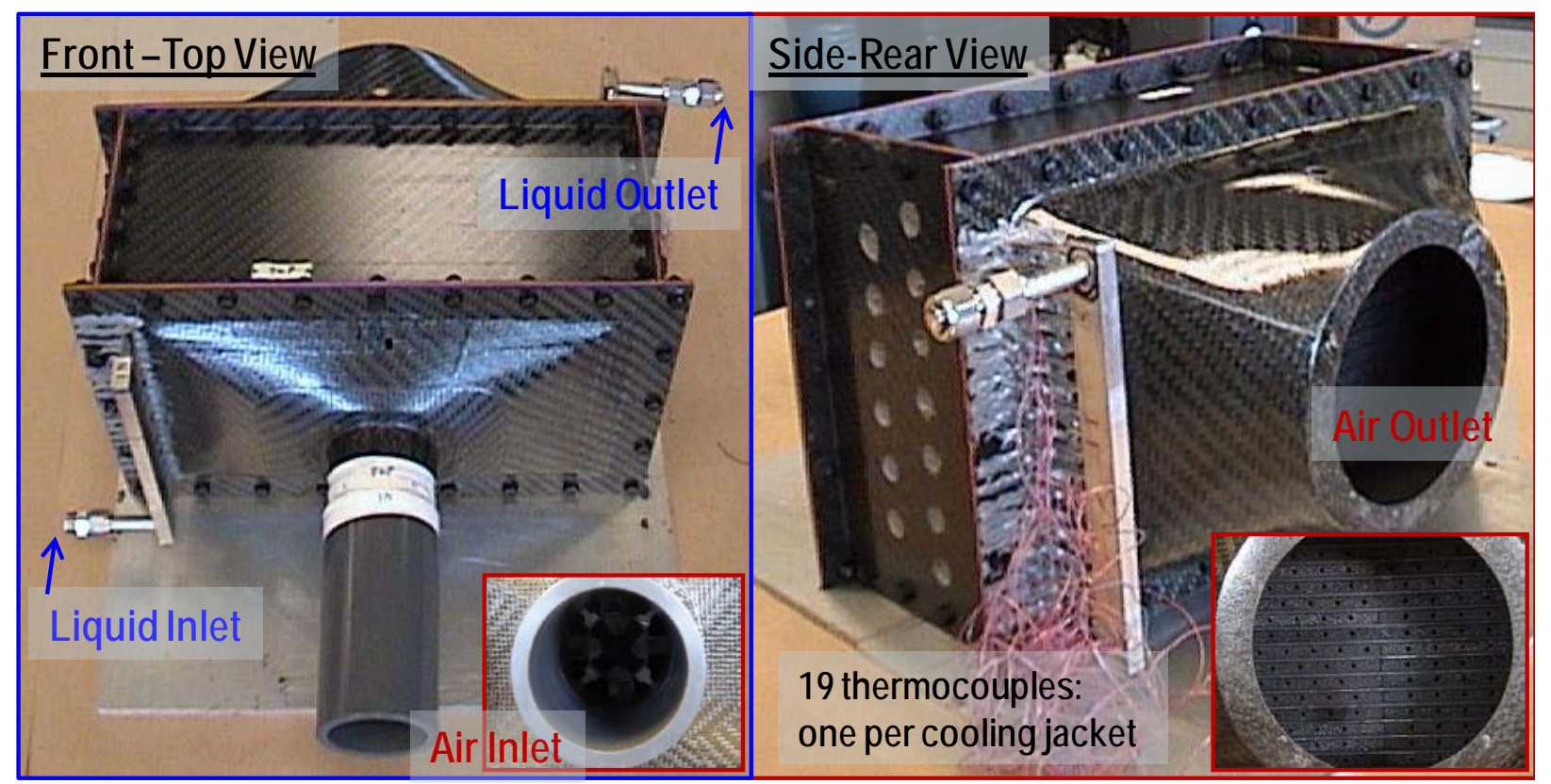

Figure 2. Overview of the composite A/L HX Prototype.

Detailed step-by-step fabrication procedures were developed for overall manufacturing of the Prototype. They are beyond the scope of this paper, but involved various precision machining and fabrication processes to prepare various components. The cooling jackets were assembled via high temperature furnace brazing, a one-step process including all components, after the brazing foil material and procedure were optimized. The brazed cooling jackets were individually inspected for leaks and pin holes which were fixed by soldering. The completed cooling jackets were then carefully laminated with the machined foam blocks using the diluted graphite cement. The assembly of the nineteen stacked modules was cured and baked in an air-circulated oven following the manufacturer's recommended conditions for the cure of the graphite cement. This core assembly was inspected and its dimensions were adjusted by filing to the design before installing the composite housing, only the core sidings and not either of the plenums initially. The external manifolds were then connected to either the inlet or outlet tube sets via soldering. When the manifold connections were completed, the entire cooling system was leak-checked with pressurized DI 
water. Both the inlet and outlet plenum were installed with silicon gasket and RTV sealant to achieve an air-tight sealing. During the Prototype assembly process, the assembly was weighed at every step, thus each component weight was accurately determined.

However, it should be noted that the selected materials and the manufacturing processes for the Prototype were not yet evaluated for the standard space qualifications. The main goal of this phase of the project was to demonstrate thermal performance potentials of the Prototype with potentially significant weight reduction.

\section{A. Weight Analysis}

Table I summarized part weights of the Prototype and compared with the EDU. As can be seen in the table, the cooling system involving cooling jackets with internal fin structure, liquid inlet and outlet tubes, external manifolds, and swage fittings became considerably heavier than that of the EDU due to a large number of plate type cooling jackets for increased heat transfer contact surfaces. However, the carbon foam core was significantly lighter because of its low density and much lower overall volume. As a result, the Prototype, 12.36 $\mathrm{Kg}(27.2 \mathrm{lbs})$, was $~ 11.2 \%$ lighter than the EDU, $13.92 \mathrm{Kg}$ (30.7 lbs), or $42.7 \%$ lighter than the metal demonstrator, $21.6 \mathrm{Kg}$ (47.5 lbs).
Table I. Details of weight analysis between EDU and Prototype.

\begin{tabular}{|l|r|r|}
\hline \multirow{2}{*}{ HX Parts } & \multicolumn{2}{c|}{ Weight, Kg } \\
\cline { 2 - 3 } & EDU & \multicolumn{1}{c|}{ Prototype } \\
\hline Cooling System, Overall & 4.89 & 6.18 \\
\hline Carbon foam core & 4.06 & 1.36 \\
\hline Composite housing, mounting brackets & 2.67 & 2.63 \\
\hline Adhesive (Dylon Graphite cement) & 0.43 & 0.27 \\
\hline Silicon RTV sealant & 0.29 & 0.07 \\
\hline Gasket (Si rubber), all & 0.20 & 0.50 \\
\hline Air Deflector & 0.07 & 0.08 \\
\hline Bolts, washer, \& nuts (Nylon) & 0.17 & 0.14 \\
\hline Mounting Bracket, Composite & 0.32 & 0.32 \\
\hline Aluminum air tubing & 0.82 & 0.82 \\
\hline Total mass & $\underline{\mathbf{1 3}}$ & $\underline{\mathbf{1 2}}$ \\
\hline \hline
\end{tabular}

\section{Performance Evaluation}

The ultimate performances of various HXs were evaluated using the specifications originally developed for the X-38 Cabin HX in this project. The required thermal specifications were as follows:

1) Liquid Coolant: De-ionized water

2) Pressure (liquid): 50 psig max operating, 75 psig min proof

3) Pressure (air): 8 to 14.7 psia

4) Performance: Maximum $10^{\circ} \mathrm{C}$ air outlet temperature given following conditions:

- $450 \mathrm{lb} / \mathrm{hr}$ water flow at $4.4^{\circ} \mathrm{C} / 35$ psia inlet (0.9 GPM)

- $1400 \mathrm{lb} / \mathrm{hr}$ air flow at $29.4^{\circ} \mathrm{C} / 14.7$ psia inlet (320 CFM)

4) Pressure drop (max) at above inlet conditions:

- Air Side: 0.4 inches of water (0.0145 psi)

- Liquid Side: 0.2 psia

5) Leakage: Not to exceed $0.01 \mathrm{cc} /$ hour water

However, for the purpose of comparison, other inlet conditions were also used, especially when the spec condition was not attainable. For this application, the inlet air was supplied after a drying process, thus there were no concerns of moisture condensation in the carbon foam modules. The DI water cooing system should be completely closed and sealed from leaking.

In most cases, the first cut analyses of the thermal data from the performance tests were conducted with the basic heat exchanger equations developed for the ideal countercurrent flow case. Since all HXs developed and tested in this paper were cross-flow HX, it was assumed that their properties calculated from the basic equations can be directly compared without further adjustment. The issue of the correction factor for non-countercurrent flow HXs is also discussed in this paper.

$$
\begin{gathered}
Q_{c}=\dot{m}_{\text {cold }} C_{p, \text { cold }}\left(T_{\text {cold,out }}-T_{\text {cold,in }}\right) \\
Q_{h}=\dot{m}_{\text {hot }} C_{p, \text { hot }}\left(T_{\text {hot,in }}-T_{\text {hot }, \text { out }}\right) \\
Q_{\text {max }}=\dot{m}_{\text {hot }} C_{p, \text { hot }}\left(T_{\text {hot }, \text { in }}-T_{\text {cold,in }}\right)
\end{gathered}
$$




$$
\begin{gathered}
\Delta T_{l m}=\frac{\left(\Delta T_{1}-\Delta T_{2}\right)}{\left[\ln \frac{\Delta T_{1}}{\Delta T_{2}}\right]} \text { where } \Delta T_{1}=T_{\text {hot }, \text { in }}-T_{\text {cold,out }} \text { and } \Delta T_{2}=T_{\text {hot }, \text { out }}-T_{\text {cold }, \text { in }} \\
\Delta T_{m}=\left[\left(T_{\text {hot }, \text { in }}+T_{\text {hot }, \text { out }}\right)-\left(T_{\text {cold }, \text { in }}+T_{\text {cold }, \text { out }}\right)\right] / 2 \\
U A=Q_{h} / \Delta T_{l m}
\end{gathered}
$$

It should be noted that the definition of this LMTD might be more relevant to the 'Shell and Tube' type HX designs.

The general structural specifications applied for this type of HXs will include, (i) loads: each component must be capable of meeting performance specifications and remaining structurally intact when subjected to a dynamic loading environment equivalent to $150 \%$ of the following static loading. The load shall be applied to the heat exchanger structural mounts, $40 \mathrm{~g}$ on any axis and $10 \mathrm{~g}$ remaining 2 axis and (ii) random vibration: each component must be able to meet its individual performance specifications while being exposed to a random vibration spectrum as given below, for 3 minutes in each axis. One of the production units will be designated as a qualification unit, and will be subjected to this environment for 3 minutes in each axis (while pressurized at proof pressure) as a qualification test. The vibration levels below correspond to the input levels which shall be applied to the component structural attach points (mounts):

$\begin{array}{ll}20 \mathrm{~Hz} & .026 \mathrm{~g} \wedge 2 / \mathrm{Hz} \\ 50 \mathrm{~Hz} & .160 \mathrm{~g} \wedge 2 / \mathrm{Hz} \\ 800 \mathrm{~Hz} & .160 \mathrm{~g} \wedge 2 / \mathrm{Hz} \\ 2000 \mathrm{~Hz} & .026 \mathrm{~g} \wedge 2 / \mathrm{Hz}\end{array}$

\section{A. Improved HX Test System}

The A/L HX test system developed earlier ${ }^{1}$, has been significantly improved, Fig. 3. The system added (i) a 4000W flow torch air heater, capable of a $20.8{ }^{\circ} \mathrm{C} \Delta \mathrm{T}$ in heating inlet air, (ii) a 2nd Chiller with a 2 nd plate $\mathrm{HX}$ on the liquid outlet loop to increase the cooling capacity resulted in a stable $6.8^{\circ} \mathrm{C}\left(44^{\circ} \mathrm{F}\right)$ at the other spec test conditions, (iii) inlet air source connected to main compressed air line to increase air flow rate capable up to 400 $\mathrm{CFM}$, and (iv) analog liquid flow meters. However, note that the $4.4{ }^{\circ} \mathrm{C}$ cold-in temperature for the spec condition was still not achievable.

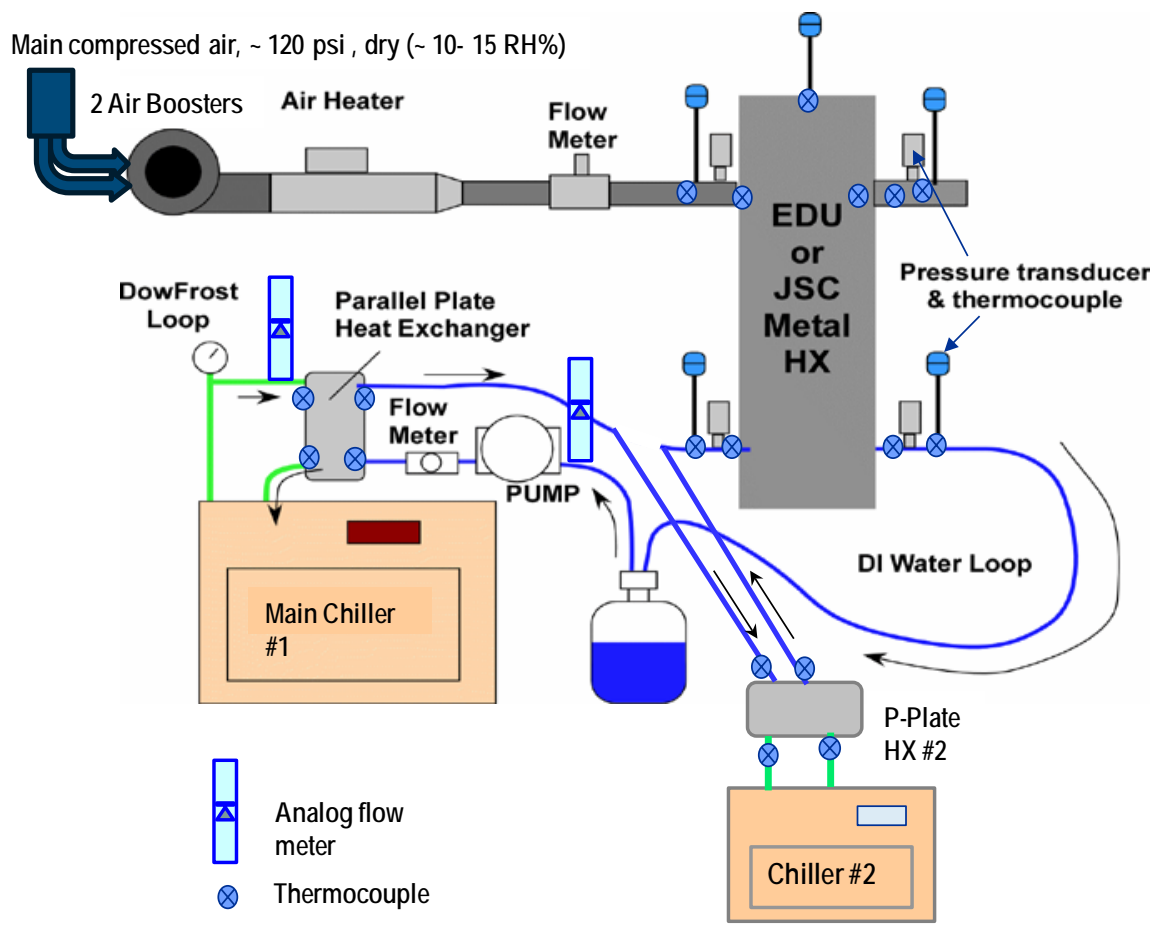

Figure 3. Outline of overall HX test system. 
In addition, accuracies of air temperatures and air pressure drop measurements were significantly improved by installing a 3.0 inch inner diameter (ID)-24 inch long air outlet tube identical to the inlet tube at the end of the outlet plenum, Fig. 4. This was to control the identical inlet and outlet air flow patterns. In the later testing, especially for studying the effects of various inlet conditions, insulation of the metal HX and the Prototype was greatly enhanced in order to minimize potential heat leaks to the environments. In the case of the Prototype as can be seen in Fig. 4, two layers of 1inch thick heavy duty PU foam insulation sheets were bonded on all external surfaces while the expanding PU foam spray was used to cover the entire external manifolds and inlet-outlet tube sets.

Instrumentation on the test system was also improved including increasing data acquisition channels to 128 . As indicated in Fig. 4, temperature of liquid and air was measured at multiple locations and averaged, e.g., three liquidin and three liquid-out temperatures, three air-in temperatures, and four air-out temperatures. In the case of the 4th thermocouple, air temperature was measured at $\sim 6$ inches inward from the end of the tube, but at 10 different locations across tube inner diameter, i.e., five locations from left to right and another five locations from top to bottom, two data points per location at 5 minute intervals.

The air pressure drop was measured with a wet/wet differential pressure transducer (Model MMDWU10WVP4D0T1A1S , 0 to 10 in-H20, Omegadyne) and a high precision analog manometer by tapping into the inlet and the outlet tubes with rigid Tygon tubing, at the same distance from the HX core. The pressure drop in liquid was also measured similarly with a wet/wet/ differential pressure transducer (Model MMDWU001VP4D0T1A1S, 0 to 1 PSI, Omegadyne) between the inlet and outlet ports.

The inlet air, mostly compressed shop air, was dry, typically less than $10 \% \mathrm{RH}$, but the humidity of outlet air was somewhat dependent on ambient temperature and humidity. The liquid and air flow meters including both digital and analog, differential pressure transducers and high precision manometer, and thermocouples were periodically calibrated and validated.

The standard test procedures including data reductions developed earlier ${ }^{1}$ were followed. Most tests were run under the steady-state condition for about 2 hours. On a few occasions, tests were run under a transient-state condition by allowing the liquid-in temperature to rise from $\sim 2{ }^{\circ} \mathrm{C}$ to $16^{\circ} \mathrm{C}$.

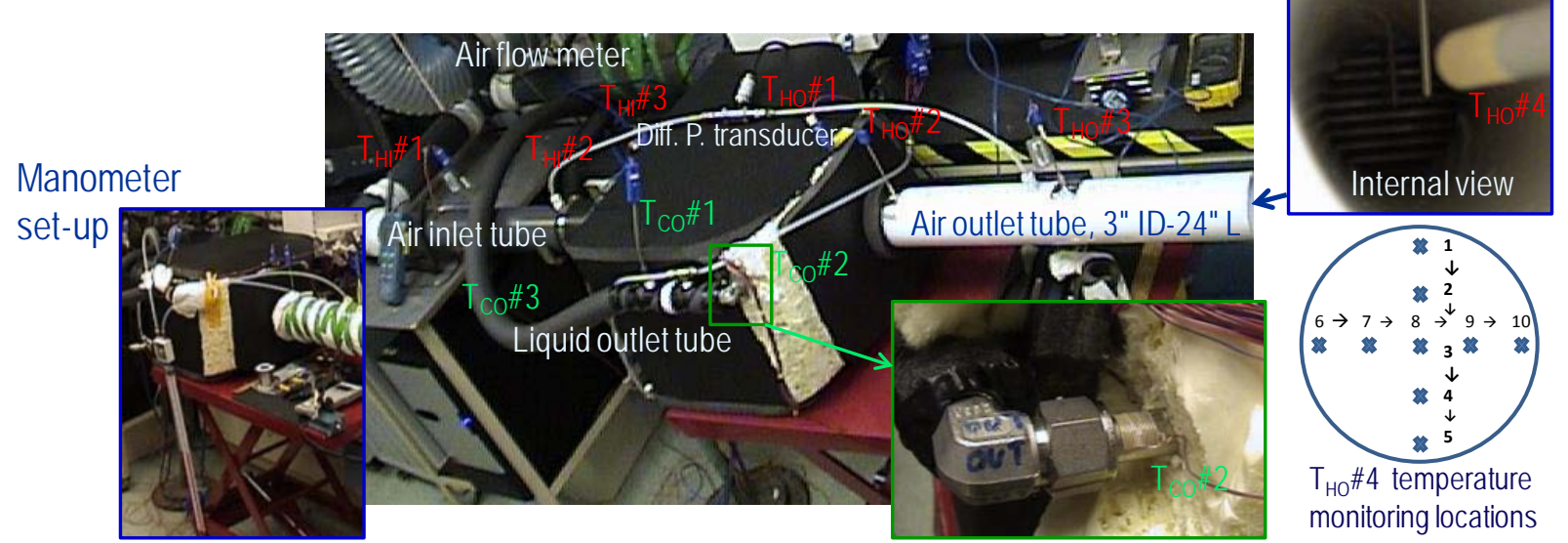

Figure 4. Instrumentation details on Prototype in the HX test system.

\section{B. Prototype Performance and Scalability}

With the newly developed Prototype design, performance was first evaluated with a subscale coupon in order to confirm its potential as well as to validate scalability. Figure 5 shows the HX coupon (top view) and test set-up. The coupon was built with only two modules which had the same cooling system and foam core with exact dimensions and configurations as the full-scale Prototype. Same materials, process conditions, and fabrication procedures were applied. Therefore, the performance of the coupon and the full-scale should be comparable by using a simple modular ratio, i.e., 2 to 19 , thus validating their scalability. 

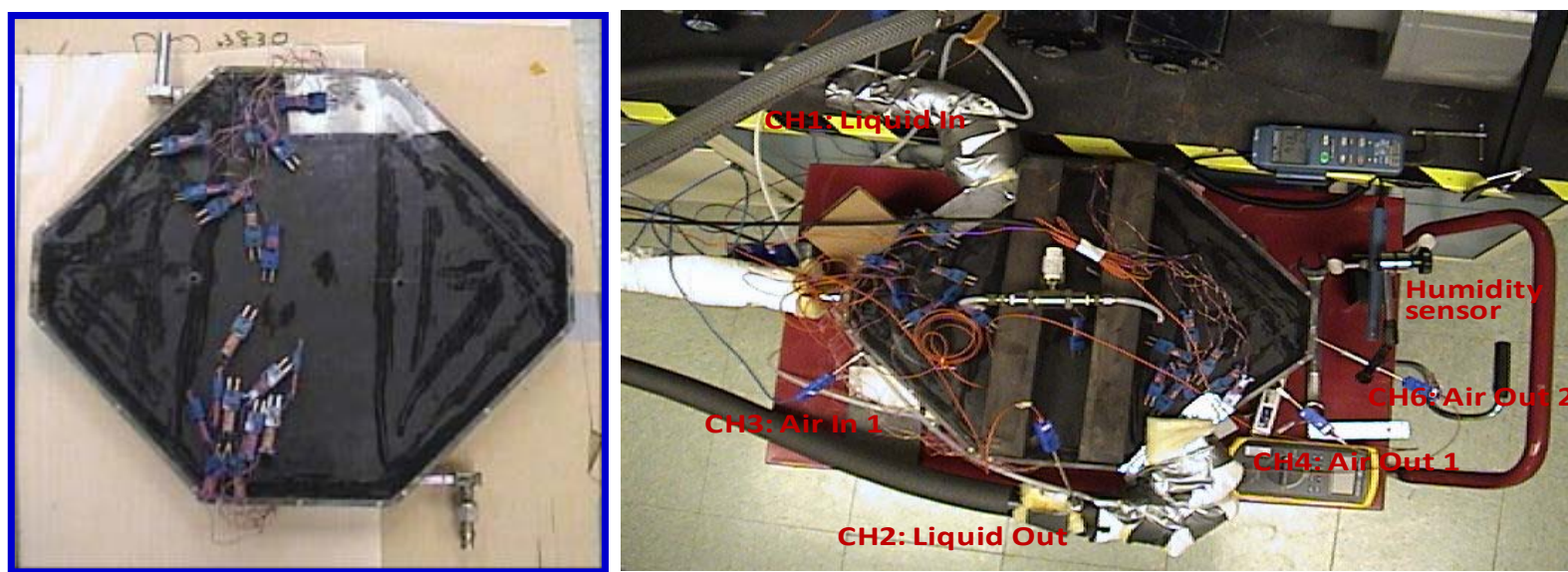

Figure 5. Prototype coupon and test set-up.

The HX core unit was enclosed with Plexiglas Plastic housing, insulated with thick rubber sheets and sealed airtight. Another goal for the coupon was to verify the uniform liquid flow distribution along the cooling system, (i) between the two cooling jackets and (ii) across the width of each cooling jacket contained multi-channel internal fin. As shown in Fig. 6, nine stick-on thermocouples were installed on top of each cooling jacket to monitor temperature changes in-situ under various inlet conditions either steady-state or transient-state. The test results confirmed the uniform distribution and rate for the both cases, (i) and (ii).

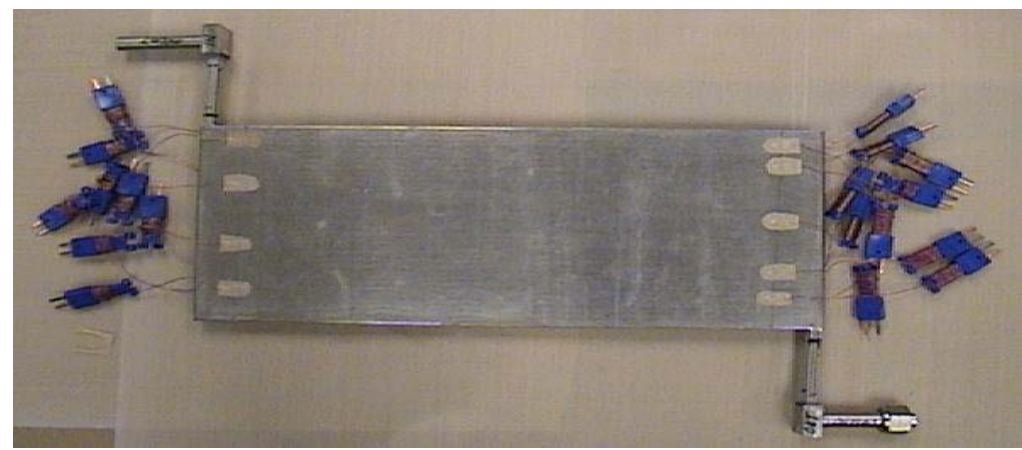

Figure 6. Thermocouple installation on cooling jackets.

After completing the coupon validation tests, a full-scale Prototype was manufactured. Performance of the Prototype was then compared with other HXs including the metal HX, the EDU, and the coupon. Table II summarizes the preliminary test results. Various inlet conditions, not necessarily meeting the specifications but rather random available conditions at the time of testing, were used since the objectives of this preliminary testing was to demonstrate feasibility via direct comparison among different HXs and to validate scalability of the Prototype design. In the case of the Prototype coupon, the results were also estimated for the full-scale unit via simple modular ratio 2:19 based on the aforementioned justifications. It should be noted that the data in the last section, highlighted yellow, were closest to the spec condition but some, highlighted red, were obtained under a transient-state condition except for the coupon data.

Overall, key findings from this preliminary evaluation are as follows:

- The Prototype HX outperformed both the EDU and the metal HX, and was the closest to the specification target $(3,450 \mathrm{~W})$ in terms of $\mathrm{Q}_{\mathrm{h}}$, thus the design was validated.

- Scalability of the Prototype design was validated since performances of the coupon and the full-scale were consistent or comparable.

- Pressure drop, $\Delta \mathrm{P}$, both air and liquid, was still slightly higher than the spec values, but the measurements might not be accurate since they were tested before the test system improvement. In the case of the water side, the higher pressure drop was likely due to the use of an array of thin inlet and outlet tubes to distribute water flow across the panel. Optimizing this design should have a significant impact of the pressure drop. 
- The Prototype, both coupon and full-scale, showed $\mathrm{Q}_{\mathrm{c}}$ lower than $\mathrm{Q}_{\mathrm{h}}$ unlike the metal $\mathrm{HX}$. This discrepancy will be further investigated. However, the $\mathrm{Q}_{\mathrm{h}} / \mathrm{Q}_{\mathrm{c}}$ ratio can be also considered as $\mathrm{HX}$ efficiency indicator since the quantity represented the capacity of HX in terms of air heat removal per cooling energy.

- The full-scale Prototype was thermally more balanced than the coupon because difference between $\mathrm{Q}_{\mathrm{h}}$ and $\mathrm{Q}_{\mathrm{c}}$ was smaller.

- It should be noted that all tests listed above were performed with lightly insulated HXs.

\section{Effects of Various Inlet Conditions}

The full-scale HX, both the Prototype and the metal demonstrator, were further evaluated. The extended performance testing was conducted after various modifications and improvements on the HX test system including the enhanced insulations of aforementioned. Specific objectives to investigate the effects of various inlet conditions including liquid-in temperature, liquid flow rate, air-in temperature, air flow rate, or their combinations were not only to determine the exact thermal performance characteristics at the spec conditions but also to understand the design-performance correlations. Most tests were run under steady state condition typically for 2 hours, but all inlet conditions were manually controlled and thus fluctuated somewhat during the course of a run. Furthermore, even with the large chiller used in these tests was incapable of removing all of the heat transferred into the water loop by the prototype. As a result, the spec liquid-in temperature, $4.4^{\circ} \mathrm{C}$ was not attainable under the steady-state condition. Similar testing and analysis were also performed on the metal HX demonstrator. Performance and behavior of the Prototype were then directly compared to those of the metal HX under similar test conditions and test matrix. In addition, a transient-state testing with a controlled heating rate of liquid-in temperature was conducted and compared to the typical steady-state testing.

Table II. Summary of performance comparison among various HXs.

\begin{tabular}{|c|c|c|c|c|c|c|c|c|c|c|c|c|c|c|c|c|}
\hline \multicolumn{2}{|c|}{ HX Performance } & \begin{tabular}{|c|} 
Air \\
Flow \\
(CFM)
\end{tabular} & \begin{tabular}{|c|} 
Liquid \\
Flow \\
(GPM) \\
\end{tabular} & $\begin{array}{l}\text { Inlet } \\
\text { Air T } \\
\left({ }^{\circ} \mathrm{C}\right) \\
\end{array}$ & \begin{tabular}{|c|} 
Inlet \\
Liquid T \\
$\left({ }^{\circ} \mathrm{C}\right)$
\end{tabular} & $\begin{array}{c}\Delta \mathrm{T} \\
\text { Air } \\
\left({ }^{\circ} \mathrm{C}\right)\end{array}$ & \begin{tabular}{|c|}
$\Delta \mathrm{T}$ \\
Liquid \\
$\left({ }^{\circ} \mathrm{C}\right)$ \\
\end{tabular} & $\begin{array}{l}\Delta \mathrm{P} \text { Air } \\
\text { (psid) }\end{array}$ & \begin{tabular}{|c}
$\Delta \mathrm{P}$ \\
Liquid \\
(psid)
\end{tabular} & $\begin{array}{c}\mathrm{Q}_{\mathrm{c}} \\
(\mathrm{W})\end{array}$ & $\begin{array}{c}Q_{h} \\
(W)\end{array}$ & $\begin{array}{l}Q_{\max } \\
\text { (W) }\end{array}$ & $Q_{h} / Q_{c}$ & $\begin{array}{c}\text { LMTD } \\
\left({ }^{\circ} \mathrm{C}\right)\end{array}$ & $\begin{array}{c}\text { UA } \\
\left(\mathrm{W} /{ }^{\circ} \mathrm{C}\right)\end{array}$ & $\begin{array}{c}\text { Specific } \\
\mathrm{Q}_{\mathrm{h}} \\
(\mathrm{W} / \mathrm{Kg})\end{array}$ \\
\hline \multicolumn{2}{|l|}{ Metal HX } & & & & & & 2 & & & 2148 & 1968 & & 92 & 7.36 & & 90 \\
\hline \multicolumn{2}{|l|}{ EDU } & & & & & -13.9 & .4 & 63 & 28 & 1697 & 1685 & 2233 & .99 & 7.23 & 233 & 121 \\
\hline Prototype & & 23.2 & 10 & 28.5 & 8.1 & -18.6 & 5.8 & 0.06 & .37 & 146 & 240 & 264 & 1.65 & 6.15 & 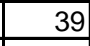 & 174 \\
\hline Coupon & 19 MOD E & 220 & .90 & & & & & & & 1383 & 2280 & 2505 & & & 371 & \\
\hline \multicolumn{2}{|c|}{ Prototype, 19 MOD } & 220 & 0.90 & 28.6 & 8.0 & -16.8 & 7.9 & 0.05 & 0.50 & 1873 & 2064 & 2523 & 1.11 & 7.39 & 280 & 167 \\
\hline \multicolumn{2}{|l|}{ Metal HX } & 248 & 89 & 9.5 & ㄴ & -17.9 & 11.7 & 0.01 & 0.81 & 2737 & 2462 & 3323 & 0.90 & 9.05 & 27 & 112 \\
\hline \multirow{2}{*}{$\begin{array}{l}\text { Prototype } \\
\text { Coupon } \\
\end{array}$} & 2 MOD & 26.9 & 10 & 29.3 & .9 & -19.0 & 9.7 & 0.07 & 0.25 & 243 & 284 & 366 & 1.17 & 9.34 & 30 & 206 \\
\hline & 19 MOD E & 256 & 90 & & & & & & & 2313 & 2699 & 3476 & & & 289 & \\
\hline \multicolumn{2}{|c|}{ Prototype, 19 MOD } & 245 & 97 & 5 & 1 & 6 & .6 & 06 & .79 & 2458 & 2666 & 3491 & L.09 & 3.89 & 300 & 216 \\
\hline \multicolumn{2}{|l|}{ Metal HX } & & & 20 & & -20.3 & 1. & . & 74 & 2296 & 2242 & 2709 & .98 & 8.43 & 266 & 102 \\
\hline \multirow{2}{*}{$\begin{array}{l}\text { Prototype } \\
\text { Coupon } \\
\end{array}$} & 2 MOD & 20.9 & 10 & 29.6 & 1 & -20.2 & 8.5 & 0.05 & 0.26 & 212 & 234 & 284 & 1.11 & 8.90 & 26 & 170 \\
\hline & 19 MOD Est. & 199 & 0.90 & & & & & & & 2013 & 2225 & 2700 & & & 250 & \\
\hline \multicolumn{2}{|c|}{ Prototype, 19 MOD } & 202 & 0.88 & 29.4 & 5.1 & -20.2 & 8.9 & 0.04 & 0.50 & 2062 & 2271 & 2730 & 1.10 & 8.51 & 267 & 184 \\
\hline \multicolumn{2}{|l|}{ Metal HX } & 317 & 96 & 27.9 & 4.4 & -15.5 & 12.9 & 0.01 & 0.73 & 3291 & 2747 & 4172 & 0.84 & 9.26 & 297 & $\overline{125}$ \\
\hline Prototype & 2 MOD & 34.5 & 0.10 & 29.4 & 4.7 & -17.6 & 11.4 & 0.09 & 0.30 & 286 & 337 & 474 & 1.18 & 9.91 & 34 & 244 \\
\hline Coupon & 19 MOD Est. & 327 & 0.90 & & & & & & & 2716 & 3202 & 4502 & & & 323 & \\
\hline \multicolumn{2}{|c|}{ Prototype, 19 MOD } & 321 & 0.91 & 28.4 & 4.4 & -18.1 & 10.6 & 0.09 & 0.50 & 2677 & 3264 & 4340 & 1.22 & 9.12 & 358 & 264 \\
\hline
\end{tabular}

Table III summarizes overall test results as well as test inlet conditions in the first four columns after the test ID number. The test \# 7-4 was the only test run partly under a transient-state because of the required liquid inlet temperature of $4.4^{\circ} \mathrm{C}$. It was the spec test but due to the transient-state the $\mathrm{Q}_{\mathrm{h}} / \mathrm{Q}_{\mathrm{c}}$ ratio was much higher. It should be noted that the LMTD and the UA values in the table were calculated based on the basic HX equations for the ideal countercurrent flow and shell and tube type HX, therefore corrections should be made for the actual Prototype configurations, i.e., cross-flow and frame and plate type HX, which is discussed in the next section.

From the data, various trend analyses were performed as functions of inlet conditions using best curve fitting regression analysis. Most analyses focused on $\mathrm{Q}_{h}$ rather than $\mathrm{Q}_{c} ; \mathrm{Q}_{h}$ values were based on air property measurements that were more accurate and reproducible than similar measurements made on the water loop. The performance of the air loop was also the main critical specification to meet,

Effects of Liquid-In Temperature at other spec conditions: Figure 7 plotted various HX properties as a function of liquid-in temperature while other inlet conditions were kept at the spec conditions, i.e., $29.4{ }^{\circ} \mathrm{C}, 323 \mathrm{CFM}$ air-in 
and 0.91 GPM DI water-in. All thermal properties showed linear relationships with the liquid-in temperature. Heat transfer quantities and LMTD decreased with increasing liquid coolant temperature while the UA value remained almost constant. Note that the two data points at low liquid-in temperatures were somewhat deviated from the regression curves. It was confirmed that the liquid flow rates used in these two tests were slightly different as indicated in the plot, but their trends were consistent with the effect of liquid flow rate on heat transfer which will be discussed later. The HX properties at the spec condition including $4.4^{\circ} \mathrm{C}$ liquid-in temperature were determined by the best curve-fit regression analysis independently and listed in the plots. The best-fit regression equations obtained in this analysis were used in determining other sets of the spec HX properties from the following trend analyses of other inlet conditions. That is, various regression curves from various inlet condition trend analyses were interrelated with each other for determining the ultimate spec HX properties. From the similar analyses, the metal HX showed similar trends except the UA and the $\mathrm{Q}_{\mathrm{h}} / \mathrm{Q}_{\mathrm{c}}$ ratio or $\mathrm{HX}$ efficiency factor in that the UA increased slightly and the ratio decreased slightly with increasing liquid-in temperature.

Table III. Summary of prototype performance test results.

\begin{tabular}{|c|c|c|c|c|c|c|c|c|c|c|c|c|c|c|c|}
\hline $\begin{array}{c}\text { Test } \\
\#\end{array}$ & \begin{tabular}{|c} 
Air \\
Flow \\
(CFM) \\
\end{tabular} & \begin{tabular}{|c|} 
Liquid \\
Flow \\
(GPM) \\
\end{tabular} & \begin{tabular}{|l|} 
Air-In \\
Temp \\
$\left({ }^{\circ} \mathrm{C}\right)$ \\
\end{tabular} & \begin{tabular}{|l|} 
Liquid- \\
$\operatorname{In} \mathrm{T}\left({ }^{\circ} \mathrm{C}\right)$
\end{tabular} & $\begin{array}{c}\Delta \mathrm{T} \\
\text { Air } \\
\left({ }^{\circ} \mathrm{C}\right) \\
\end{array}$ & \begin{tabular}{|c|}
$\Delta \mathrm{T}$ \\
Liquid \\
$\left({ }^{\circ} \mathrm{C}\right)$
\end{tabular} & $\begin{array}{l}\Delta \mathrm{P} \text { Air } \\
\text { (psid) }\end{array}$ & $\begin{array}{c}\Delta \mathrm{P} \\
\text { Liquid } \\
\text { (psid) }\end{array}$ & $\begin{array}{c}Q_{c} \\
(W)\end{array}$ & $\begin{array}{c}Q_{h} \\
(W)\end{array}$ & $\begin{array}{l}Q_{\max } \\
(W)\end{array}$ & $\mathrm{Q}_{\mathrm{h}} / \mathrm{Q}_{\mathrm{c}}$ & $\begin{array}{c}\text { LMTD } \\
\left({ }^{\circ} \mathrm{C}\right)\end{array}$ & $\begin{array}{c}\mathrm{UA} \\
\left(\mathrm{W} /{ }^{\circ} \mathrm{C}\right)\end{array}$ & $\begin{array}{c}\text { Specific } \\
Q_{h} \\
(\mathrm{~W} / \mathrm{Kg})\end{array}$ \\
\hline $6-1$ & 322 & 0.92 & 29.3 & 8.0 & -15.2 & 9.7 & 0.57 & 0.35 & 2366 & 2720 & 3816 & 1.15 & 8.55 & 318 & 220 \\
\hline $6-2$ & 323 & .77 & 29.4 & 8.2 & -16.8 & 5.9 & 0.57 & 0.96 & 2765 & 3016 & 3811 & 1.09 & 8.76 & 344 & 244 \\
\hline $6-3$ & 322 & 2.47 & 29.3 & 8.9 & -16.6 & 4.3 & 0.57 & 1.16 & 2763 & 2982 & 3657 & 1.08 & 8.51 & 350 & 241 \\
\hline $6-4$ & 219 & 1.77 & 29.4 & 8.0 & -18.5 & 4.6 & 0.27 & 0.83 & 2138 & 2244 & 2601 & 1.05 & 7.97 & 282 & 182 \\
\hline $6-5$ & 220 & 2.62 & 29.2 & 8.2 & -18.5 & 3.1 & 0.27 & 1.35 & 2171 & 2266 & 2565 & 1.04 & 7.74 & 293 & 184 \\
\hline $6-6$ & 120 & 1.77 & 29.5 & 7.9 & -20.0 & 2.7 & 0.09 & 1.03 & 1257 & 1326 & 1429 & 1.06 & 6.93 & 191 & 107 \\
\hline $6-7$ & 121 & 2.60 & 29.4 & 8.0 & $\mid-20.1$ & 2.0 & 0.09 & 1.25 & 1405 & 1346 & 1439 & 0.96 & 6.85 & 196 & 109 \\
\hline $7-1$ & 323 & 0.92 & 29.4 & 13.1 & \begin{tabular}{|l}
-11.7 \\
\end{tabular} & 7.3 & 0.57 & 0.37 & 1768 & 2108 & 2935 & 1.19 & 6.58 & 320 & 171 \\
\hline $7-2$ & 323 & 0.91 & 29.4 & 18.0 & -8.2 & 5.1 & 0.58 & 0.35 & 1235 & 1470 & 2039 & 1.19 & 4.54 & 324 & 119 \\
\hline $7-3$ & 334 & 0.98 & \begin{tabular}{|l|}
30.2 \\
\end{tabular} & 6.0 & -17.3 & 10.8 & $\mathrm{n} / \mathrm{a}$ & \begin{tabular}{|l|}
0.37 \\
\end{tabular} & 2776 & 3206 & 4474 & 1.16 & \begin{tabular}{|l}
9.78 \\
\end{tabular} & 328 & 260 \\
\hline $7-4$ & 323 & 0.86 & 29.6 & 4.4 & -17.9 & 11.7 & $\mathrm{n} / \mathrm{a}$ & 0.31 & 2630 & 3215 & 4515 & 1.22 & 10.08 & 319 & 260 \\
\hline $7-5$ & 221 & 0 & 29.3 & 18.1 & -9.1 & 3. & 0.27 & 0.35 & 940 & 1112 & 1375 & 1.18 & 4.20 & 264 & 0 \\
\hline $7-6$ & 220 & 0.89 & \begin{tabular}{|l|}
29.3 \\
\end{tabular} & 6.2 & -18.5 & 8.4 & 0.27 & 0.32 & 1959 & 2258 & 2820 & 1.15 & 8.73 & 258 & 183 \\
\hline $\begin{array}{l}7-7 \\
\end{array}$ & 221 & 0.94 & 29.0 & 5.3 & -19.1 & 8.3 & 0.27 & 0.37 & 2057 & 2347 & 2919 & 1.14 & 8.97 & 262 & 190 \\
\hline $7-8$ & 122 & 0.94 & 29.4 & 4.4 & -22.3 & 56 & 0.09 & 0.38 & 1381 & 1507 & 1696 & 1.09 & 8.63 & 175 & 122 \\
\hline $8-1$ & 220 & 0.93 & 29.4 & 8.1 & $\mid-17.2$ & 7.5 & 0.27 & 0.37 & 1829 & 2101 & 2602 & 1.15 & 7.99 & 263 & 170 \\
\hline $8-2$ & 121 & 0.91 & 29.4 & 7.9 & -19.1 & 4.9 & 0.09 & 0.37 & 1171 & 1280 & 1439 & 1.09 & 7.33 & 175 & 104 \\
\hline $8-2$ & 119 & 0.91 & 29.4 & 7.9 & -19.2 & 4.7 & 0.09 & 0.38 & 1127 & 1267 & 1420 & 1.12 & 7.31 & 173 & 103 \\
\hline $9-1$ & 322 & 0.91 & 26.0 & 8.1 & -12.7 & 8.4 & 0.57 & 0.35 & 2016 & 2296 & 3254 & 1.14 & 7.21 & 318 & 186 \\
\hline $9-2$ & 322 & 0.92 & \begin{tabular}{|l}
23.1 \\
\end{tabular} & 8.0 & -10.7 & 7.2 & 0.57 & 0.36 & 1739 & 1954 & 2746 & 1.12 & 5.96 & 328 & 158 \\
\hline $9-2$ & 321 & 0.91 & 23.1 & 8.1 & $\mid-10.7$ & 7.0 & 0.58 & 0.37 & 1691 & 1948 & 2728 & 1.15 & 5.93 & 329 & 158 \\
\hline
\end{tabular}

The combined effects of the liquid-in temperature and the air flow rate were also analyzed, especially at 220 CFM and 120 CFM air flow rates. In both cases, all HX properties maintained the linear relationships with liquid-in temperature but at different rates. The slopes of the regression curves lowered with decreasing air flow rate. The $\mathrm{Q}_{\mathrm{h}} / \mathrm{Q}_{\mathrm{c}}$ ratio slightly increased with liquid-in temperature, but decreased with decreasing air flow rate. 

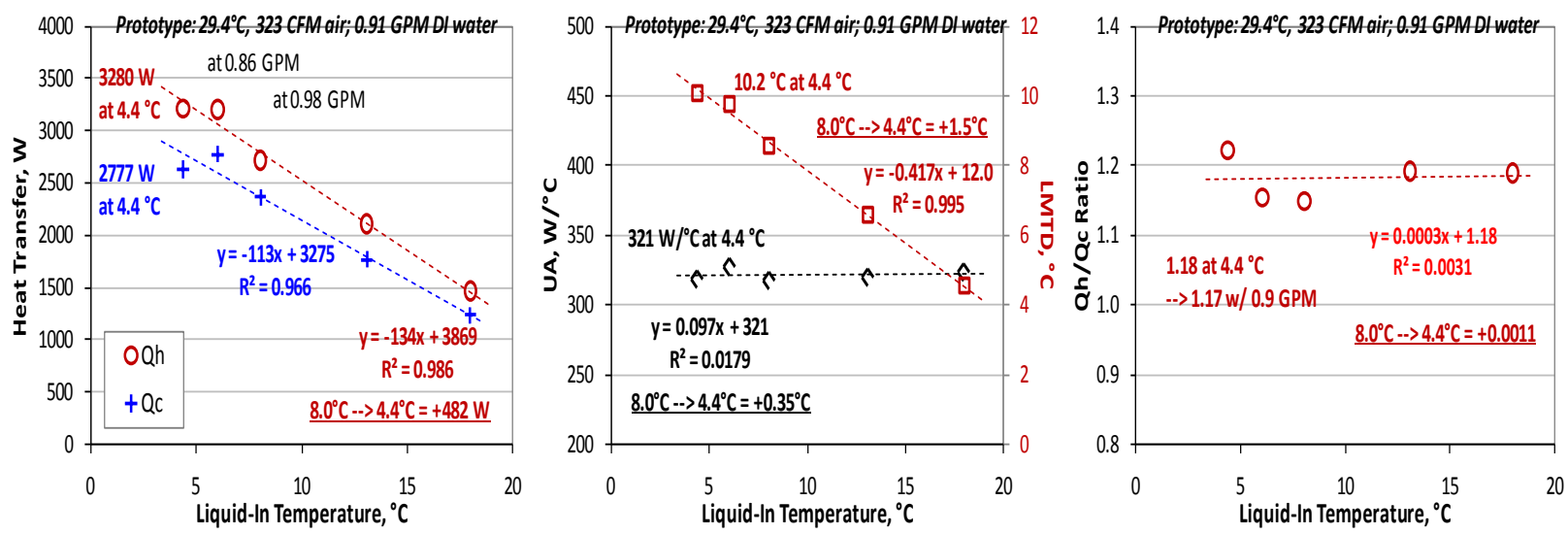

Figure 7. Effects of liquid-in temperature on HX properties of the full-scale Prototype.

Effects of air-in temperature: All HX properties showed linear relationships with the Air-in temperature, Fig. 8. Heat transfer quantities and LMTD increased with increasing air-in temperature while the UA value slightly decreased, but the $\mathrm{Q}_{\mathrm{h}} / \mathrm{Q}_{\mathrm{c}}$ ratio remained almost constant. Again, the second set of the spec HX properties, i.e., at the inlet air temperature of $29.4^{\circ} \mathrm{C}$ for this analysis was determined by a best curve-fit regression analysis but taking into account the differences between the tested liquid-in temperature, $8.0^{\circ} \mathrm{C}$, and the spec liquid-in temperature, 4.4 ${ }^{\circ} \mathrm{C}$, estimated from the previous regression analysis, e.g., in $\mathrm{Q}_{\mathrm{h}}$ calculation, added $482 \mathrm{~W}$ for changing the liquid-in temperature from $8.0^{\circ} \mathrm{C}$ to $4.4^{\circ} \mathrm{C}$. The results are listed in the plots. From the similar analyses, the metal HX showed the same trends for most properties including the $\mathrm{Q}_{\mathrm{h}} / \mathrm{Q}_{\mathrm{c}}$ ratio.
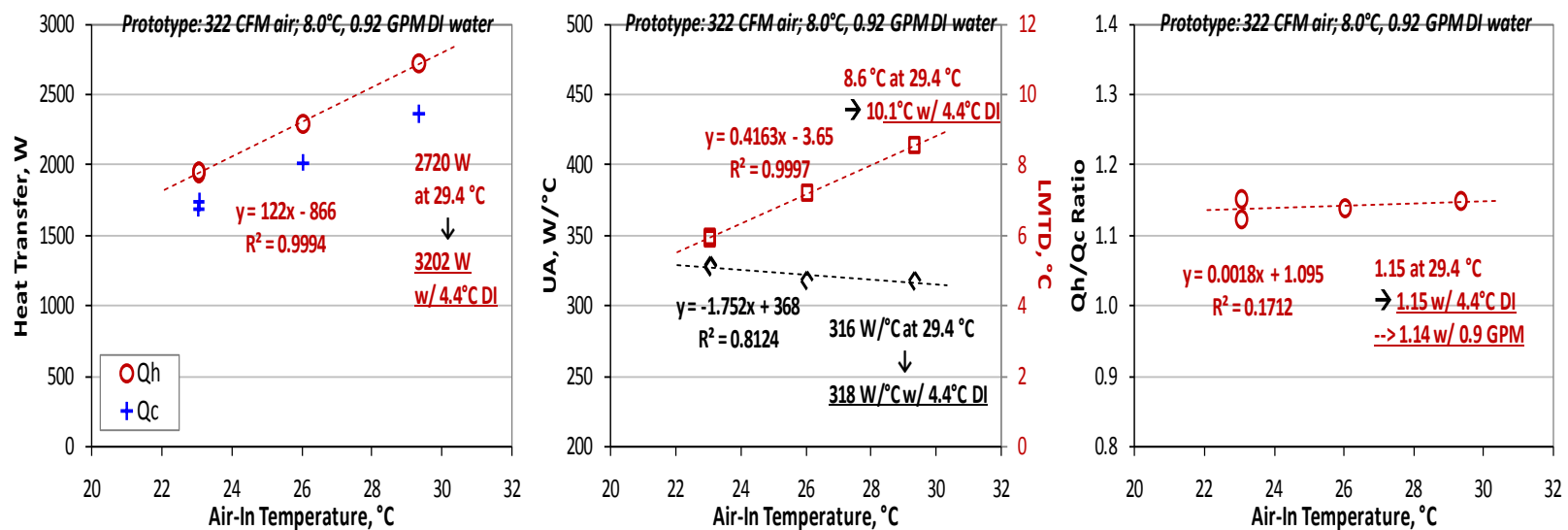

Figure 8. Effects of air-in temperature on HX properties of the full-scale Prototype.

Effects of liquid flow rate: All HX properties showed nonlinear relationships with respect to the liquid flow rate, mostly a second-order polynomial, Fig. 9. Its effect on heat transfer quantities was rather insignificant, especially at higher flow rates, i.e., indicating a limit in the effectiveness of liquid flow rate on heat transfer. The $\mathrm{Q}_{\mathrm{h}} / \mathrm{Q}_{\mathrm{c}}$ ratio was lowered with increasing liquid flow rate. Similarly, another set of the spec HX properties, i.e., at 0.9 GPM for this analysis was determined by a best curve-fit regression analysis, then adjusted with the changes for the spec liquid-in temperature estimated from the previous regression analysis, e.g., in $\mathrm{Q}_{\mathrm{h}}$ calculation, added $+508 \mathrm{~W}$ for changing the liquid-in temperature from $8.2^{\circ} \mathrm{C}$ to $4.4^{\circ} \mathrm{C}$. From similar analyses, the metal $\mathrm{HX}$ followed the same nonlinear trends for most properties except the $\mathrm{Q}_{\mathrm{h}} / \mathrm{Q}_{\mathrm{c}}$ ratio. The ratio of the metal HX remained almost constant. Further investigation will be conducted to identify the different behaviors between the metal HX and the Prototype.

The combined effects of the liquid flow rate and the air flow rate were also analyzed, especially at 220 CFM and 120 CFM air flow rates. The similar nonlinear relationships were observed at both lower air flow rates, but the changes were less with decreasing the air flow rate. It was also observed that the $\mathrm{Q}_{\mathrm{h}} / \mathrm{Q}_{\mathrm{c}}$ ratio or $\mathrm{HX}$ efficiency decreased toward unity with lowering air flow rate, and also decreased with increasing liquid flow rate. 

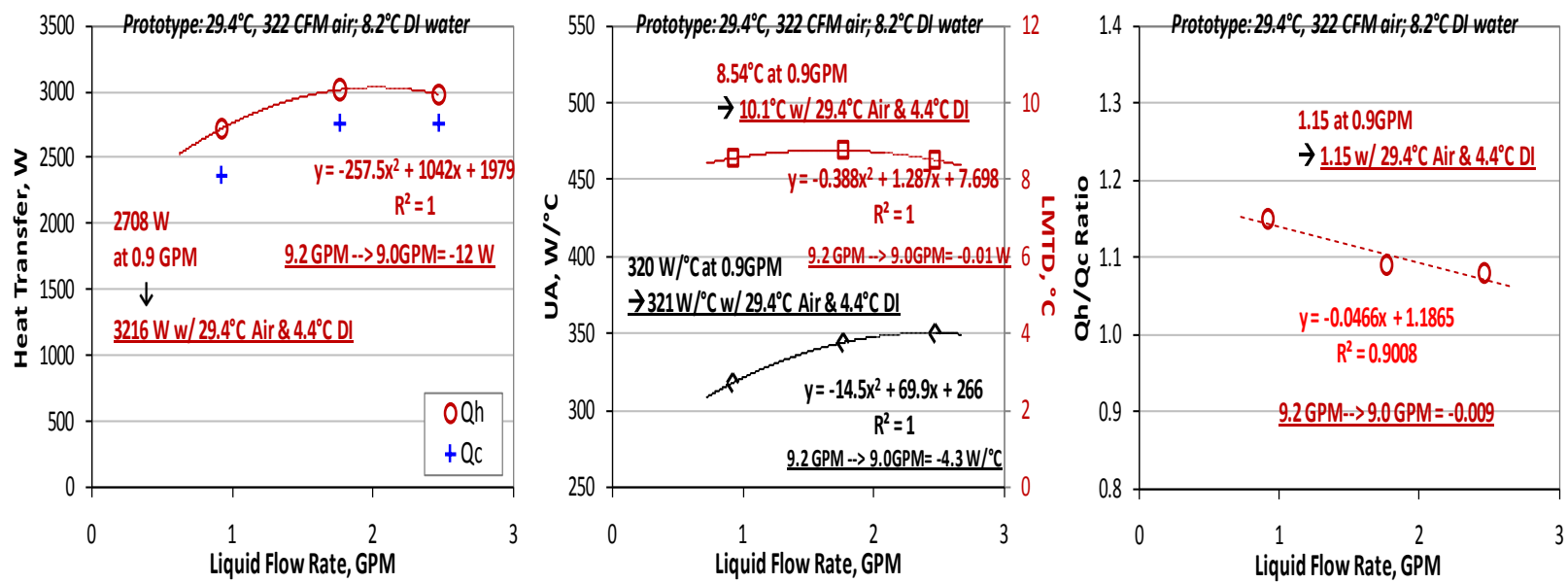

Figure 9. Effects of liquid flow rate on HX properties of the full-scale Prototype.

Effects of air flow rate: Effects of air flow rate on the HX properties were similar to those of liquid flow rate in that the trends were nonlinear, mostly a second-order polynomial, Fig. 10. However, its effect on heat transfer quantities was rather significant in the range studied from 120 CFM to 320 CFM. The $\mathrm{Q}_{\mathrm{h}} / \mathrm{Q}_{\mathrm{c}}$ ratio slightly increased with increasing air flow rate. The last set of the spec HX properties, i.e., at 320 CFM in this analysis was determined by a best curve-fit regression analysis, and then adjusted with the changes for the spec liquid-in temperature estimated from the previous regression analysis, e.g., in $\mathrm{Q}_{\mathrm{h}}$ calculation, added $+482 \mathrm{~W}$ for changing the liquid-in temperature from $8.0^{\circ} \mathrm{C}$ to $4.4^{\circ} \mathrm{C}$. The metal $\mathrm{HX}$ followed the same nonlinear trends for most properties including the $\mathrm{Q}_{\mathrm{h}} / \mathrm{Q}_{\mathrm{c}}$ ratio.
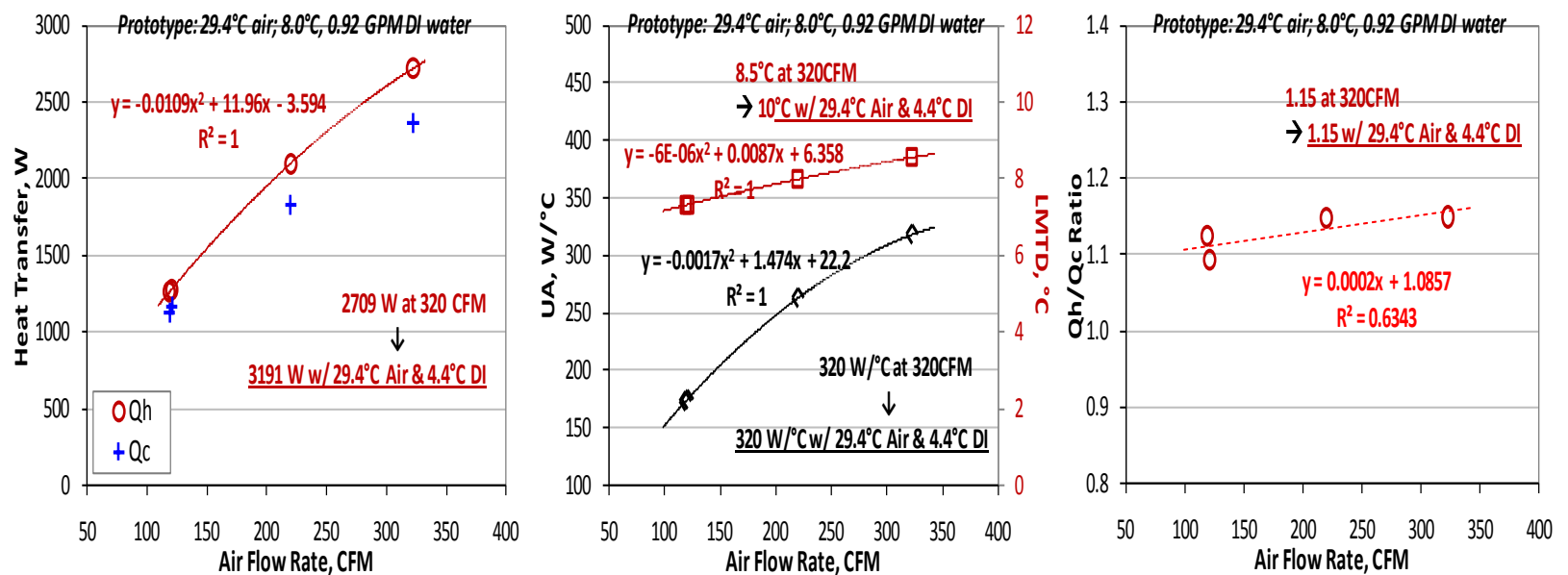

Figure 10. Effects of air flow rate on HX properties of the full-scale Prototype.

\section{Performance at the specification Condition}

All spec HX properties from various trend analyses for various inlet conditions in the previous section agreed very well, within a standard deviation less than $1-2 \%$. The ultimate HX properties at the exact spec conditions, primarily $\mathrm{Q}_{\mathrm{h}}, \mathrm{Q}_{\mathrm{h}} / \mathrm{Q}_{\mathrm{c}}$ ratio, LMTD, and UA, were then determined by averaging the four independently extrapolated spec values from the various trend analyses of the experimental data for both the Prototype and the metal demonstrator. Table IV lists the final mean spec properties and standard deviations. The pressure drop, $\Delta \mathrm{P}$, of air and liquid were obtained from a best curve-fit regression analysis of experimental data as a function of flow rate while all other inlet conditions were kept at the spec conditions. $\mathrm{Q}_{c}$ and temperature changes, $\Delta \mathrm{T}$, in air and liquid were back calculated using the basic HX equations, (1) and (2).

Both the metal $\mathrm{HX}$ and the Prototype showed equally comparable thermal performances. They did not meet the required $\mathrm{Q}_{\mathrm{h}}, 3,450 \mathrm{~W}$, but achieved $93.4 \%$ of the target. However, specific $\mathrm{Q}_{\mathrm{h}}$ of the composite Prototype was $77 \%$ 
higher than that of the metal HX demonstrator. Comparing most test results, the enhanced insulation on the Prototype did not significantly affect its performance unlike the metal $\mathrm{HX}$, specifically the $\mathrm{Q}_{\mathrm{h}} / \mathrm{Q}_{\mathrm{c}}$ ratio or $\mathrm{HX}$ efficiency factor. In the case of the metal HX, the enhanced insulation moved the ratio slightly higher than 1 from below 1. Thus, the difference between $\mathrm{Q}_{\mathrm{h}}$ and $\mathrm{Q}_{\mathrm{c}}$ was considered as the unique characteristics of those HXs for further analyses even though it violated the energy balance. Also, note that the LMTD, and thus the UA values in the table, were calculated based on the basic HX equations for an ideal countercurrent flow and shell and tube type HX, therefore corrections should be made for the actual Prototype configurations, i.e., cross-flow and frame and plate type HX, which is discussed in the next section.

Table IV. Ultimate HX properties at the spec conditions.

\begin{tabular}{|c|c|c|c|c|c|c|c|c|c|c|c|c|c|}
\hline \multicolumn{2}{|c|}{ HX Tyре } & $\begin{array}{c}\Delta \mathrm{T} \\
\text { Air } \\
\left({ }^{\circ} \mathrm{C}\right)\end{array}$ & $\begin{array}{c}\Delta \mathrm{T} \\
\text { Liquid } \\
\left({ }^{\circ} \mathrm{C}\right)\end{array}$ & $\begin{array}{l}\Delta \mathrm{P} \text { Air } \\
\text { (psid) }\end{array}$ & $\begin{array}{c}\Delta \mathrm{P} \\
\text { Liquid } \\
\text { (psid) }\end{array}$ & $\begin{array}{c}Q_{c} \\
(W)\end{array}$ & $\begin{array}{c}Q_{h} \\
(W)\end{array}$ & $Q_{h} / Q_{c}$ & $\begin{array}{c}\text { LMTD } \\
\left({ }^{\circ} \mathrm{C}\right)\end{array}$ & $\begin{array}{c}\mathrm{UA} \\
\left(\mathrm{W} /{ }^{\circ} \mathrm{C}\right)\end{array}$ & \begin{tabular}{c|}
$\mathrm{U}$, \\
$\mathrm{W} / \mathrm{K} \cdot$ \\
$\mathrm{m} 2$
\end{tabular} & $\begin{array}{c}\text { Specific } \\
Q_{\mathrm{h}} \\
(\mathrm{W} / \mathrm{Kg})\end{array}$ & $\begin{array}{c}\% \\
\text { change }\end{array}$ \\
\hline \multirow{2}{*}{ Metal HX } & A verage & -18.1 & 12.9 & 0.16 & 0.33 & 3063 & 3224 & 1.05 & 8.76 & 365 & & 147 & \\
\hline & St. Dev. & & & & & & 48 & 0.02 & 0.05 & 4 & & & \\
\hline \multirow{2}{*}{$\begin{array}{l}\text { Comp HX } \\
\text { Prototype }\end{array}$} & A verage & $\mid-18.1$ & 11.8 & 0.58 & 0.36 & 2802 & 3222 & 1.15 & 10.10 & 320 & 128 & 261 & 77 \\
\hline & St. Dev. & & & & & & 40 & 0.01 & 0.08 & 1 & 1 & & \\
\hline
\end{tabular}

The performances of the full-scale HXs at the spec conditions can also be compared by the conventional T-Q diagrams, Fig. 11. The required performance at the spec condition calculated by the basic HX equations would be $\mathrm{Q}_{\mathrm{h}}=\mathrm{Q}_{\mathrm{c}}=3,450 \mathrm{~W}, \mathrm{LMTD}=7.77^{\circ} \mathrm{C}, \mathrm{UA}=444 \mathrm{~W} /{ }^{\circ} \mathrm{C}$, and $\mathrm{T}_{\text {liquid-out }}=18.9^{\circ} \mathrm{C}$, but those are for an ideal $/$ theoretical $\mathrm{HX}$, e.g., perfectly adiabatic, truly countercurrent flow system with no residual effects. For the actual HXs, not perfectly adiabatic and cross-flow configuration, $\mathrm{Q}_{\mathrm{h}}$ was not equal to $\mathrm{Q}_{\mathrm{c}}$ but characterized by the unique ratio, so-called efficiency factor, from the extensive analyses of the actual experimental data. Based on the efficiency factor determined at the spec conditions, the required performance would be $\mathrm{Q}_{\mathrm{h}}=3,450 \mathrm{~W} ; \mathrm{Q}_{\mathrm{c}}=3,285 \mathrm{~W}$ for the metal $\mathrm{HX}$ or $\mathrm{Q}_{\mathrm{c}}=3,000 \mathrm{~W}$ for the Prototype; $\mathrm{LMTD}=8.06^{\circ} \mathrm{C}$ for the metal or $8.53^{\circ} \mathrm{C}$ for the Prototype; $\mathrm{UA}=428 \mathrm{~W} /{ }^{\circ} \mathrm{C}$ for the metal or $404 \mathrm{~W} /{ }^{\circ} \mathrm{C}$ for the Prototype. The back-calculated $\mathrm{T}_{\text {liquid-out }}$ values at the Spec was $18.24{ }^{\circ} \mathrm{C}$ for the metal or $17.05{ }^{\circ} \mathrm{C}$ for the Prototype. The three cases are compared in the left plot in Figure 11. The right plot shows the best performance of the metal and Prototype at the spec conditions. From these T-Q diagrams, it is clear that the required heat transfer duty involves a temperature cross. For such a severe temperature cross or the cold side fluid exiting much higher than the hot side air exiting, the plate and frame type compact HX performs significantly better than the typical shell and tube type HX. This was why the prototype (Plate \& frame type HX) performed much better than the earlier composite EDU (Shell \&Tube type HX).

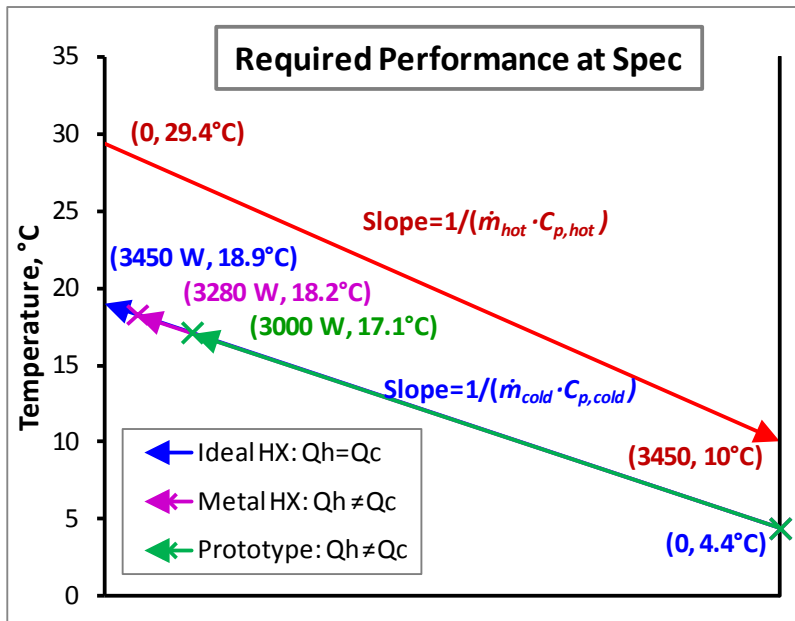

Q, Heat Movement

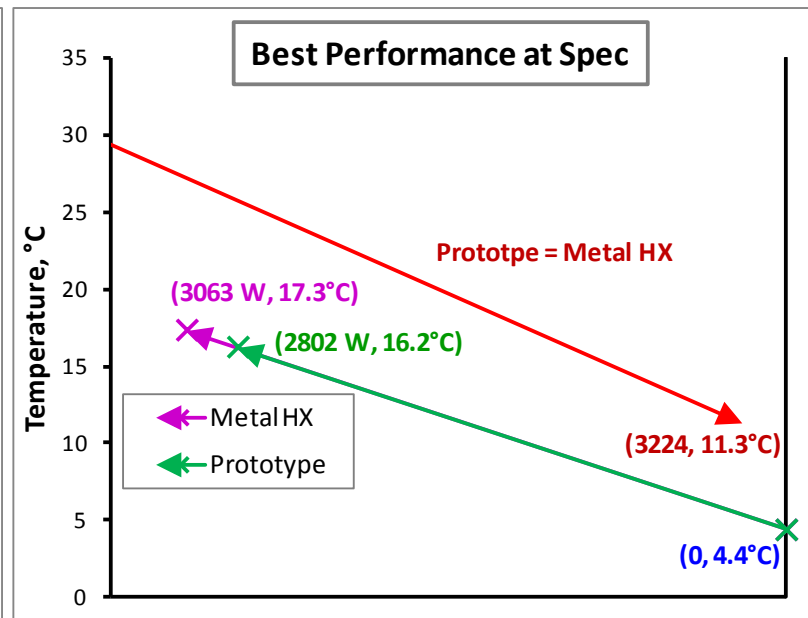

Q, Heat Movement

Figure 11. T-Q Diagrams of required and best performance of various HXs.

The Prototype suffered with a higher pressure drop than the metal HX in both air and liquid side, Table IV. The $\Delta \mathrm{P}$ will be mitigated by foam material optimizations and design modifications including more systematic air channel 
design. The prototype was designed to meet both the thermal and the structural requirements, but accomplishing the thermal requirements was the main priority, especially for the first prototype, thus other performance requirements such as pressure drop will be considered for the next version.

\section{E. Temperature Correction Factor}

In general, for the non-countercurrent flow HXs such as the metal HX and the Prototype, the Eq. (6) takes the form, $U A=Q_{h} /\left(\Delta T_{l m} \bullet f\right)$, where $f$ is a temperature correction factor used to adjust the LMTD values, i.e., 1 for the truly countercurrent flow, otherwise it is typically ranged $0.75-0.97$. The $\mathrm{f}$ values could be established for various HX designs/configurations in terms of temperature efficiency and ratio of heat flow, but were not available for the studied HXs due to design complexity, thus a rough calculation was performed. Based on the best performances of the HXs at the spec conditions, they equally achieved $93.4 \%$ of the required heat transfer target. Assuming the same performance rate, the corrected UA values could be $400 \mathrm{~W} /{ }^{\circ} \mathrm{C}$ for the metal $\mathrm{HX}$ or $377 \mathrm{~W} /{ }^{\circ} \mathrm{C}$ for the Prototype instead of $365 \mathrm{~W} /{ }^{\circ} \mathrm{C}$ or $320 \mathrm{~W} /{ }^{\circ} \mathrm{C}$, respectively, which were measured but calculated by the heat exchanger equations for the perfectly countercurrent flow.

From the above equation, $f=Q_{h} / \Delta T l m / U A_{\text {Corrected }}=U A_{\text {Measured }} / U A_{\text {Corrected, }}$, i.e., for the metal $\mathrm{HX}, f=365 / 400=$ 0.91 and for the Prototype, $f=320 / 377=0.85$

Typically, a HX design was acceptable if its $\mathrm{f}$ were larger than 0.8 . Therefore, $\mathrm{UA}$ of the metal $\mathrm{HX}$ and the Prototype at the spec condition after taking the cross-flow configuration into account will be $404 \mathrm{~W} /{ }^{\circ} \mathrm{C}$ and 375 $\mathrm{W} /{ }^{\circ} \mathrm{C}$, respectively, or their corrected LMTD would be $7.98^{\circ} \mathrm{C}$ and $8.59{ }^{\circ} \mathrm{C}$, respectively.

\section{F. Scale-up Analysis}

As described in the earlier section, scalability of the Prototype design was validated experimentally via comparing thermal performances between the 2-module coupon and the 19-module full scale HX and followed the simple modular ratio. Based on the scalability validation, the scale-up factor for the modular Prototype to meet the required heat transfer $\left(3,450 \mathrm{~W} \mathrm{Q}_{\mathrm{h}}\right.$ or $404 \mathrm{~W} /{ }^{\circ} \mathrm{C}$ UA at the spec condition) can be determined by the following simple modular ratio relations. At the spec condition, the current Prototype with the19-module achieved $\mathrm{Q}_{\mathrm{h}}=3222$ $\mathrm{W}$, i.e., $169.6 \mathrm{~W} /$ module, or in terms of $\mathrm{UA}=375 \mathrm{~W} /{ }^{\circ} \mathrm{C}$ from $U A=Q_{h} /\left(\Delta T_{l m}{ }^{\bullet} f\right)=3222 /(10.1 \times 0.85)$, i.e., 19.74 $\mathrm{W} /{ }^{\circ} \mathrm{C} /$ module. From either $\mathrm{Q}_{\mathrm{h}}$ or UA values, the scale-up Prototype can only need 20.4 or 21 modules to achieve the specification target. However, the scale-up analysis should also involve scaling of the air flow rate per module when the total number of modules was increased since the heat transfer was a strong function of air flow rate. The left plot in Figure 12 shows the change in air flow rate per module against the number of modules in the Prototype under the spec overall inlet air flow rate of 320 CFM. Note that the change becomes less with higher number of modules, especially above 20. The right plot in Figure 12 summarizes how to determine the correct number of modules for the scale-up Prototype. The relation between air flow rate per module and heat transfer, $\mathrm{Q}_{\mathrm{h}}$, in the Prototype design was determined from (i) the experimental data obtained under the spec conditions or most close to the spec from both the 2-module coupon and the 19-module Prototype (Tables II and III), (ii) extrapolated data from the trend analyses for 120 and 220 CFM air flow cases, and (iii) the ultimate spec properties in Table IV. In the cases of the data not exactly at the spec condition but close, all from Table II, were slightly adjusted based on those trend analyses. Note that all data from either the 2-module coupon or the 19-module Prototype agreed well with the trend displayed by a $2^{\text {nd }}$ order polynomial equation. This consistency suggests again that the design is scalable by module. The heat transfer-air flow rate relation was then correlated with the target condition described in those two terms, i.e., $\left(\mathrm{Q}_{\mathrm{h}}\right.$ per module $) \times$ (number of module $)=3450 \mathrm{~W}$ or $\mathrm{y} \cdot(320 / \mathrm{x})=3450$. i.e., $\mathrm{y}=10.781 \mathrm{x}$. By solving the quadratic equation, the correct air flow rate per module to achieve the target was 13.31 CFM, i.e., 24 modules at the spec overall inlet air flow rate, 320 CFM. Therefore, the scale-up Prototype will need 24 modules. The estimated weight of the 24-module Prototype will be about $14.7 \mathrm{Kg}(32.4 \mathrm{lbs})$. However, its actual weight can be considerably lower with further weight optimization of various components, such as cooling jacket, external manifold, composite housing, or carbon foam core, without compromising thermal performance or structural requirements. 

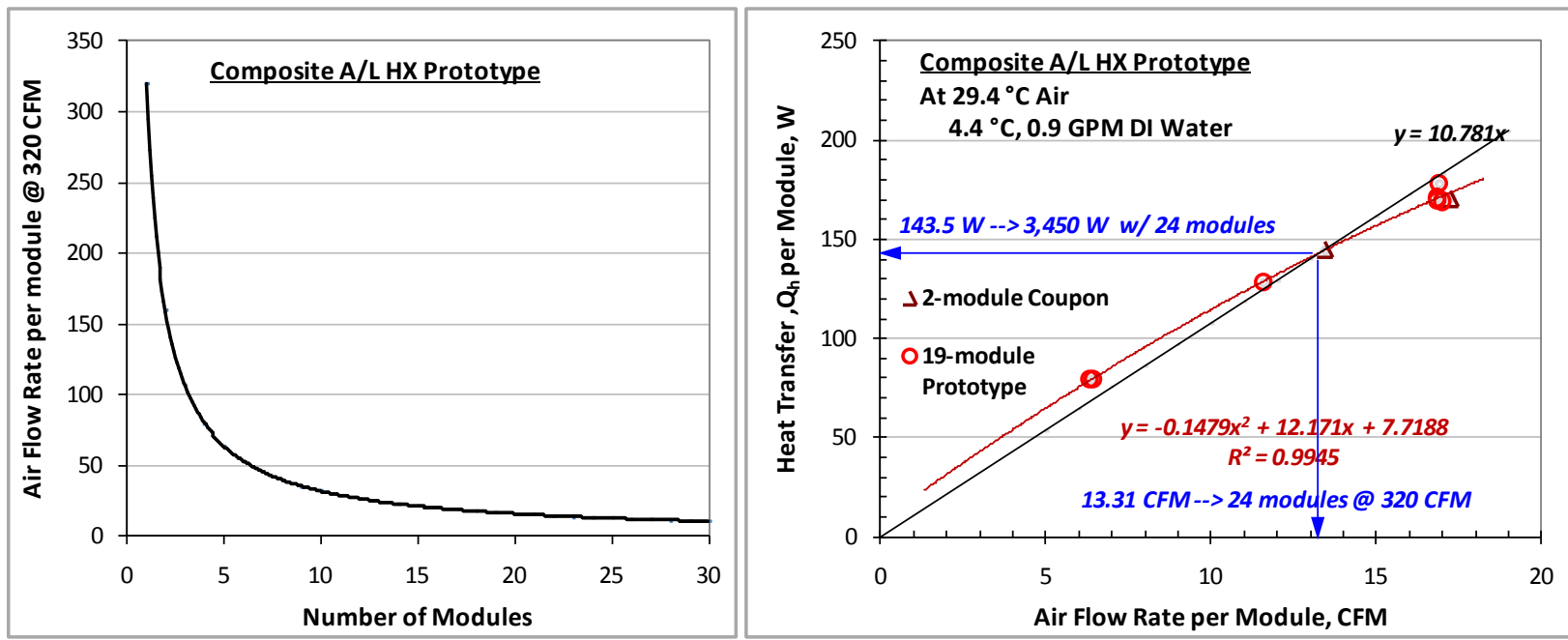

Figure 12. Scale-up analysis involving proper scaling of air flow rate per module.

\section{Summary and Conclusions}

Progress in the development of the lightweight composite A/L HX is presented. Based on findings and recommendations from the EDU, a first version Prototype was designed, manufactured, and extensively tested for performance evaluation with a significantly improved HX test system. A subscale 2-module coupon was also fabricated to validate scalability. The Prototype utilized a similar thermally conductive open-cell carbon foam material to that used in the EDU but with lower density. The prototype also adopted a novel high-efficiency cooling system with significantly increased heat transfer contact surface areas, improved fabricability and manufacturability, which resulted in the overall weight reduction over the EDU. Designs of individual components of the Prototype were experimentally verified in terms of functionality and performance.

Key conclusions drawn from the Prototype development work to date include:

- Design and manufacturing procedures developed for the Prototype were proved to be viable

- The Prototype, at $27.23 \mathrm{lbs}(12.4 \mathrm{Kg})$, was 11.2 \% lighter than the EDU, (30.67 lbs (13.9 Kg)), and $42.7 \%$ lighter than the metal demonstrator, which weighed $47.5 \mathrm{lbs}(21.6 \mathrm{Kg})$. However, to warrant the saving, its higher air pressure drop ( 0.58 psid vs. 0.16 psid of the metal HX) has to be mitigated by foam material optimizations and design modifications including more systematic air channel design

- Scalability of the Prototype design was validated experimentally by comparing manufacturability and performance between the 2-module coupon and the 19-module Prototype

- Effects of various inlet conditions were determined for the Prototype and the metal HX

- All HX properties showed linear relationships with liquid-in temperature or Air-in temperature, but nonlinear relationships with liquid flow rate or air flow rate, mostly a second-order polynomial.

- Both the Prototype and the metal demonstrator showed similar relationships with all inlet conditions, but their trends/slopes were not always similar, e.g., in the metal HX, the UA increased slightly and the $\mathrm{Q}_{\mathrm{h}} / \mathrm{Q}_{\mathrm{c}}$ ratio or $\mathrm{HX}$ efficiency factor decreased slightly with increasing liquid-in temperature. Overall, they showed equally comparable thermal performances.

- For the Prototype, the $\mathrm{Q}_{\mathrm{h}} / \mathrm{Q}_{\mathrm{c}}$ ratio remained constant with air-in temperature, slightly increased with liquid-in temperature, but decreased with increasing liquid flow rate or decreasing air flow rate. The ratio decreased toward unity with lowering air flow rate, and also decreased with increasing liquid flow rate.

- The effects of air flow rate were significant within the range studied, 120 to 320 CFM, while the effects of liquid flow rate were rather insignificant, especially at higher flow rates, 1.5 - 2.7 GPM.

- The HX properties at the spec condition were determined by the best curve-fit regression analysis independently. Various regression curves from various inlet condition trend analyses were interrelated with each other for determining the ultimate spec HX properties.

- From the ultimate HX properties at the exact spec conditions 
- Both the metal HX and the Prototype showed comparable thermal performances.

- $\quad$ Neither met the required $\mathrm{Q}_{\mathrm{h}}, 3,450 \mathrm{~W}$, but achieved $93.4 \%$ of the target. However, specific $\mathrm{Q}_{\mathrm{h}}$ of the Prototype was $77 \%$ higher than that of the metal HX demonstrator.

- The enhanced insulation on the Prototype did not affect its performance in contrast to the metal $\mathrm{HX}$, specifically the $\mathrm{Q}_{\mathrm{h}} / \mathrm{Q}_{\mathrm{c}}$ ratio or $\mathrm{HX}$ efficiency factor. In the case of the metal $\mathrm{HX}$, the enhanced insulation moved the ratio slightly higher than 1 from below 1 . The ratio was considered as the unique characteristics of those HXs for further analyses.

- The conventional T-Q diagram analysis indicated why the prototype (Plate \& frame type HX) performed much better than the earlier composite EDU (Shell \&Tube type HX).

- The Prototype exhibited higher pressure drops than the metal HX on both air and liquid side.

- Assuming the same performance rate, $93.4 \%$ on UA values, the temperature correction factors estimated were 0.91 for the metal HX and 0.85 for the Prototype.

- After taking the HX efficiency factor, the temperature correction factor, and scaling air flow rate into account, a Prototype scaled up to achieve the specification heat transfer, 3,450 W, would need 24 modules. The estimated weight of the 24-module Prototype will be about $14.7 \mathrm{Kg}$ with current design and materials, or considerably lighter with further weight optimization of various components.

\section{Acknowledgments}

The authors would like to thank Ryan Stephan, NASA-JSC, for guidance and support of funding from the Advanced Thermal Controls Project under the Exploration Technology Development Program (ETDP) and Life Support and Habitation Systems (LSHS) Heat Acquisition Project, ETDD (Enabling Technologies Development and Demonstration); Mike Meador, Mark Hyatt, and Gary Ruff, NASA-GRC, for project management and logistic supports; Brian Motil, NASA-GRC, for reviewing Prototype design, performance testing and analyses; Tim Ubienski and Anthony Kapucinski, NASA-GRC/SLI, for design review and machining various parts; Daniel Scheiman, Bob Paleaz, Rahul Mital (summer intern), NASA-GRC, for supporting assembly and thermal performance testing; and Peter Stansberry and Ed Pancost, GrafTech International Holdings LLC for supply of the conductive carbon foam materials and technical supports. Authors also want to acknowledge Steve Prout, Bob Muto, American Brazing for Brazing/assembling of cooling jackets; David Haushalter, Robinson Fin Machine, Inc; Joe Jingle, Best Fab Co.; Frank Star, Fastar EDM Inc for supplying parts for the cooling systems; Gary Patz, Patz Materials and Tech (PMT) for Fabrication of F1/T700 composite prepreg; and Greg Brookes, Sean Brookes, Sherwood Advanced Composite; Jim Hickey, UDRI; Jeff Lucas, MINCO for Design optimization and manufacturing of composite housings.

\section{References}

${ }^{1}$ Shin, E.E., and Johnston, J.C. "Design and Development of Lightweight Air-Liquid Composite Heat Exchangers for Space Exploration Applications," Proceedings of ICES 103: Thermal and Environmental Control of Crewed Lunar Exploration Vehicles, 40th International Conference on Environmental Systems, Paper \#: AIAA-2010-6136, 11 - 15 July 2010, Barcelona, Spain.

${ }^{2}$ Shin, E.E., “GRC Composite Heat Exchanger (HX) Development - Air/Liquid Coupon Recommendation Report,” Final report, the Exploration Technology Development Program’s (ETDP) Advanced Thermal Controls Project, September 29, 2008.

${ }^{3}$ Klett, J.W., and Burchell, T.D., "High thermal conductivity, mesophase pitch derived carbon foam,” Eurocarbon '98: Science and Technology of Carbon, Published French Carbon Group, Strasbourg, France, July 5-9, 1998.

${ }^{4}$ Druma, A.M., Alam, M.K., and Druma, C., “Analysis of thermal conduction in carbon foams," International Journal of Thermal Sciences, Vol 43, 2004, pp 689-695.

${ }^{5}$ Duston, C., Seghi, S., Watts, R., Carney, B., "Strength Enhancement And Application Development of Carbon Foam for Thermal Management Systems,” AF CF_NSMMS_200406.pdf, http://www.techassess.com/tech/foam/CF_NSMMS_200406.pdf (accessed 03 May 2010).

${ }^{6} \mathrm{Yu}$, Q., Straatman, A.G., and Thompson, B.E., “Carbon-foam finned tubes in air-water heat exchangers,” Applied Thermal Engineering Vol 26, 2006, pp 131-143.

${ }^{7}$ Klett, J., "High Thermal Conductivity Graphite Foams for Compact Lightweight Radiators," www.acmnevada.com/Technical/Radiator\%20Graphite-Foam.pdf (accessed 03 May 2010).

${ }^{8}$ Klett, J., "Heat Exchangers for Heavy Vehicles Utilizing High Thermal Conductivity Graphite Foams," SAE Technical Paper Series, 2000-01-2207, The Engineering Society for Advancing Mobility Land See Air and Space International.

${ }^{9}$ Lin, Y.R., "Experimental Study on Heat Transfer and Pressure Drop of Recuperative heat Exchangers Using Carbon Foam,” Journal of Heat Transfer, Vol. 13, September 2010, 091902-1 - 10. 